\section{Effect of ECS on one-trial learning and on the partial reinforcement effect*}

\author{
A. GRAN'T YOUNG and H. D. DAY \\ Louisiana State University, Baton Rouge, La. 70803
}

Thirty-two naive male albino rats were trained to leverpress for sucrose using a discrete trial procedure. Half of the Ss were trained on a continuous reinforcement schedule (CRF), and the other half were trained on a variable-ratio schedule (VR). Following acquisition, for half of the $\mathrm{Ss}$ in each group a leverpress produced footshock followed by ECS. For the remaining Ss, a leverpress produced footshock only. While ECS produced apparent amnesia for the footshock in CRF-trained Ss, it did not produce amnesia for the footshock in VR-trained Ss. Further, VR-trained Ss which received ECS failed to show the partial reinforcement effect in extinction.

When electroconvulsive shock (ECS) is administered shortly after a learning experience, the result appears to be retrograde amnesia (RA) for that learning experience (Lewis, 1969). This ECS-produced disruption of recent memory has been accounted for by a memory consolidation hypothesis which suggests that time is required for the memory trace to become permanently fixed (Glickman, 1961; McGaugh, 1966). It is assumed that immediately following sensory input some type of process (i.e., reverberatory activity) maintains the memory trace until permanent fixation of the trace is completed. If head trauma, such as ECS, is experienced by the organism during the short-term process, the consolidation process is disrupted such that permanent fixation of the memory trace does not occur.

In order to separate the amnesic effect of ECS from any aversive effects, a typical procedure is to administer aversive stimulation, such as footshock, upon the emission of a learned response. The aversive stimulation results in a suppressed rate of responding; however, if ECS is administered shortly after the aversive stimulation, the apparent result is RA for this one-trial learning.

Recently, Young \& Galluscio (1970a) reported findings that do not support a consolidation interpretation of the effects of ECS. In that study, two groups of rats were trained to leverpress, one group on a continuous reinforcement schedule (CRF) and the other on a fixed ratio schedule (FR 5 ). Upon completion of acquisition, on pretest day, a leverpress was followed by footshock. For half the Ss in each group, footshock was followed by ECS; the other half received no ECS. All Ss were then tested during an

*This research was supported in part by a grant from the University Council on Research, LSU, to the first author. extinction session. Results showed that during extinction the CRF group which received ECS following footshock made significantly more responses than did the $C R F$ group which received footshock only. However, both FR 5 groups showed significantly suppressed response rates, not significantly different from each other, although one group had received footshock plus ECS, and the other group had received footshock only. Thus ECS did not eliminate suppression of response rate following training on a FR schedule.

A partial reinforcement schedule typically generates a higher acquisition response rate in a free operant situation than does a CRF schedule. Hence, to determine whether this higher response rate is a critical variable with respect to the effects of ECS, Young \& Galluscio (1970b) replicated their first experiment but, in the second experiment, used a discrete trial procedure to control response rates. Using the latter technique, the acquisition response rate for FR-trained Ss was significantly lower than that for CRF-trained Ss, and results showed that ECS apparently produced RA in both groups. The authors suggested that in earlier studies, where ECS failed to reduce response suppression for FR-trained Ss, the absence of response suppression may have been due to the higher acquisition response rate generated by the FR schedule.

More recently, however, in a similar experiment, Young \& Day (1970) found that ECS eliminated, or reduced, response suppression for rats trained on a variable ratio (VR) schedule in a free operant situation, even though these VR-trained Ss had a significantly higher acquisition response rate than did the CRF-trained Ss. In that study, the authors suggested that acquisition response rate still may be a critical variable and noted that the acquisition response rate for their VR-trained Ss was considerably lower than that reported by Young and Galluscio for their FR-trained Ss.

A second finding of the Young and Galluscio, Young and Day studies was the failure of FR-and VR-trained Ss which experienced ECS to show the partial reinforcement effect (PRE)-the increased resistance to extinction shown by Ss trained on a partial reinforcement schedule.

The present study was designed to determine: (1) the effect of ECS following VR training when a discrete trial procedure to control acquisition response rate is used, and (2) whether or not Ss so trained will show the PRE following ECS treatment. SUBJECTS

The Ss were 32 naive male albino rats, $175-200 \mathrm{~g}$ in weight at the start of the experiment.

\section{APPARATUS}

The apparatus consisted of two identical Scientific Prototype operant chambers, each enclosed in a sound-insulated, ventilated cubicle. Each operant chamber had a grid floor, and fitted on the end wall was a retractable lever and a liquid dipper that dispensed $.01 \mathrm{ml}$ of a $40 \%$ sucrose solution used as reinforcement. All E-controlled events were operated by an electronic programming device. PROCEDURE

The Ss, selected randomly from the LSU colony, were placed in individual cages and kept on an ad lib food and water schedule for 4 days, after which they were placed on a food-deprivation schedule of $10 \mathrm{~g}$ of Purina chow every $24 \mathrm{~h}$. Water was available in the cages at all times, and Ss were fed approximately $10 \mathrm{~min}$ after each experimental session.

From the 5 th to the 9 th day $S$ were handled in pairs for $5 \mathrm{~min}$ daily, and on the 10th day Ss began magazine training on a VI $30-\mathrm{sec}$ schedule. Experimental periods consisted of 20 presentations of the dipper and were continued for 4 days. On the 14th day all $S s$ were conditioned to leverpress, and on the following day they were allowed to make 100 reinforced responses. On the 16 th day Ss were divided randomly into two groups, VR and CR, and acquisition training was begun. For the VR group acquisition was under a VR 2 reinforcement schedule, and for the $C R$ group acquisition was under a CRF schedule, All Ss were given 100 leverpresses daily for 10 days. A discrete trial procedure was used and the lever, which required $4 \mathrm{sec}$ to retract and extend fully, was inoperative during retraction.

On the day following completion of acquisition, each group was subdivided 
Table 1

Table 2

Mean Number of Lever Presses in Extinction

\begin{tabular}{ccc} 
Group & $\begin{array}{c}\text { First } \\
\text { Minute }\end{array}$ & Total \\
\hline VR (ECS) & 15.3 & 101.00 \\
CR (ECS) & 16.6 & 73.90 \\
VR (SO) & 8.0 & 81.60 \\
CR (SO) & 1.3 & 27.10 \\
\hline
\end{tabular}

\begin{tabular}{cccc}
\multicolumn{2}{c}{ Mean } & Number of & Responses Per Minute \\
\hline Group & $\begin{array}{l}\text { Acqui- } \\
\text { sition }\end{array}$ & $\begin{array}{c}\text { First Minute } \\
\text { Test }\end{array}$ & $\begin{array}{c}\text { Total } \\
\text { Test }\end{array}$ \\
\hline CR (ECS) & 45.10 & 16.62 & 7.39 \\
CR (SO) & 51.69 & 1.25 & 2.71 \\
VR (ECS) & 32.57 & 15.25 & 10.10 \\
VR (SO) & 30.42 & 8.00 & 8.16 \\
\hline
\end{tabular}

randomly, resulting in the following four groups $(\mathrm{N}=8)$ :

Groups $C R(E C S)$ and VR(ECS). On treatment day, Ss in these two groups were fitted with a harness. Fine wire from an ECS source, which entered the operant chamber from the top, was connected to the harness and from the harness to microalligator clips which attached to S's ears. The harness arrangement permitted complete freedom of movement to all parts of the operant chamber. The first leverpress produced a $9-\mathrm{mA}$ footshock of $2 \mathrm{sec}$ duration, delivered through the grid floor, and the lever retracted. The offset of footshock initiated the onset of a 50-mA 500-msec ECS delivered through the earclip electrodes.

Groups $C R(S O)$ and $V R(S O)$. For Ss in these two groups, treatment was identical to the two groups above except that footshock was not followed by ECS.

On the day following treatment, Ss were subjected to a $10-\mathrm{min}$ extinction session. During extinction, the stimulus conditions were the same as during acquisition except that the dipper was inoperative. RESULTS

The total number of responses made by each $S$ in extinction was recorded at the end of the first minute and at the end of the $10-\mathrm{min}$ period. The results for the first minute showed that more responses were made by Group CR(ECS), followed in order by Groups VR(ECS), VR(SO), and $\mathrm{CR}$ (SO). These data were subjected to an analysis of variance which showed that only the treatment effect was significant $(p<.01)$. Group comparisons (t tests) showed that CR(ECS) vs CR(SO) was significant beyond the .01 level, but the comparison VR(ECS) vs VR(SO) was not significant at the .05 level.

The results for the $10-\mathrm{min}$ period showed that more responses were made by Group VR(ECS), followed in order by Groups VR(SO), CR(ECS), and $\mathrm{CR}(\mathrm{SO})$. These data were subjected to an analysis of variance which showed that both main effects, treatment and reinforcement schedule, were significant beyond the .01 level. The Treatment by Schedule interaction did not reach significance at the .05 level, $F(1,28)=2.61$. Group comparisons (t tests) showed that
CR(ECS) vs CR(SO) and VR(SO) vs $\mathrm{CR}(\mathrm{SO})$ were significant beyond the .01 level. The comparisons VR(ECS) vs VR(SO) and VR(ECS) vs CR(ECS) were not significant at the .05 level, The mean number of responses in extinction for all groups is shown in Table 1.

Table 2 shows group mean response rates on the last 2 days of acquisition, the first minute of extinction, and for the full $10-\mathrm{min}$ extinction period. Although there were no differences in acquisition response rates for the $\mathrm{SO}$ and ECS groups, the VR-trained Ss were significantly slower than the CR-trained Ss ( $p<.05$, Mann-Whitney $\mathrm{U})$. A comparison of response rates for the first minute on test day, and for the full 10-min test period, showed Group CR(SO) to be significantly slower than Group CR(ECS) $(p<.01$, Mann-Whitney U); however, the comparison of response rates for Groups VR(ECS) vs VR(SO) and VR(ECS) vs CR(ECS) were not significant at the .05 level (Mann-Whitney U). DISCUSSION

The finding that the CR(ECS) group made significantly more responses in extinction than did the CR(SO) group is typical and agrees with earlier findings.

A critical finding of this study is that the immediate administration of ECS following footshock did not eliminate response suppression in the VR(ECS) group. These results are in agreement with those of Young \& Galluscio (1970a), and do not support a memory consolidation hypothesis. Presumably, if ECS-produced RA is due to disruption of a memory consolidation process, this result should be obtained regardless of the acquisition reinforcement schedule.

A second critical finding of this study is the failure of the VR(ECS) group to show the PRE when compared with the CR(ECS) group. The VR(ECS) group did make more responses during the test period than did the CR(ECS) group, but the difference was small and not statistically significant. This finding is in agreement with those of Young \& Galluscio (1970a) and Young \& Day (1970).

The present findings, along with those reported by Young \& Galluscio (1970a) and Young \& Day (1970) suggest that the effect of ECS is independent of acquisition response rate. In two studies (Young \& Galluscio, 1970b; Young \& Day, 1970), ECS apparently produced RA whether acquisition response rate was low or high, while in the present study ECS did not produce RA following a low acquisition response rate, nor did it in the Young \& Galluscio (1970a) study following a high acquisition response rate.

The combined findings further suggest that the effect of ECS is not the disruption of a memory trace resulting in $\mathrm{RA}$, but rather, perhaps through disinhibition (Chorover \& Schiller, 1965), the effect is an inflated rate of responding or a perseveration of responding in extinction. Since this effect would be more noticeable for CRF-trained Ss, which typically cease responding far sooner than Ss trained on a partial reinforcement schedule (PR), the result would be a reduction in the difference between the $C R$ and $P R$ groups, and a loss of the PRE. This would also account for the fact that frequently PR-trained Ss given ECS do not show a significantly greater number of responses in extinction than do PR-trained Ss which do not receive $E C S$, because the increased perseveration of responding caused by ECS, over and above that produced by a PR schedule, cannot be detected in a relatively short test session.

\section{REFERENCES}

CHOROVER, S. L., \& SCHILLER, P. H Short-term retrograde amnesia in rats. Journal of Comparative \& Physiological Psychology, 1965, 59, 73-78.

GLICKMAN, S. E. Perseverative neural processes and consolidation of the neural trace. Psychological Bulletin, 1961, 58 218-233.

LEWIS, D. J. Sources of experimental amnesia. Psychological Review, 1969,76, 461-472.

McGAUGH, J. L. Time-dependent processes in memory storage. Science, 1966, 153 , 1351-1358.

YOUNG, A. G.. \& GALLUSCIO, E. H. Failure of ECS to produce retrograde amnesia following partial reinforcement training. Psychonomic Science, 1970a, $18,175-176$.

YOUNG, A. G., \& GALLUSCIO, E. H Effect of ECS on one-trial leaming following continuous and partial reinforcement training. Psychonomic Science, $1970 \mathrm{~b}, 21,43-44$.

YOUNG. A. G.. \& DAY.H. D. ECS effects following continuous and partial reinforcement training. Psychonomic Science, 1970, 21,131-132. 